\title{
DIFERENTES MÉTODOS NO ENSINO DE HISTÓRIA E A IMPORTÂNCIA DOS RECURSOS DIDÁTICOS
}

\author{
Maria Angélica Perez Bellucci ${ }^{1}$ \\ Edson Bellucci ${ }^{2}$ \\ Renata Suman ${ }^{3}$
}

Resumo: O presente trabalho consiste em analisar as mudanças que aconteceram no ambiente escolar tão importante no processo de aprendizagem. Mostrar as diferenças entre o modelo de ensino tradicional e o construtivista, novas maneiras de se aprender história, (não mais memorizando), mas sendo estimulada a construção do conhecimento por meio de discussões que despertem e estimulem a criticidade no aluno, pensando, descobrindo, interagindo com os colegas e professores, chegando, assim, a conclusões próprias sobre o assunto abordado. E, também, apresentar a importância dos recursos didáticos, métodos interativos e diferenciados.

Palavras-chave: Material didático; Método Tradicional; Método construtivista; Diferenças.

\footnotetext{
1 Universidade do Vale do Paraíba, Brasil. E-mail: mapbellucci@yahoo.com.br.

2 Universidade do Vale do Paraíba, Brasil. E-mail: edsbell@yahoo.com.br.

3 Universidade do Vale do Paraíba, Brasil. E-mail: suman.renata@gmail.com.
} 